\title{
Barreiras fronteiriças contra o princípio de non-refoulement: a inacessibilidade do território e da determinação do status de refugiado
}

\author{
Laís Gonzales de Oliveira*
}

0 trabalho buscou verificar se o princípio de non-refoulement seria aplicável aos indivíduos não reconhecidos formalmente como refugiados e se o impedimento de acesso ao território do Estado de destino violaria tal princípio, além de analisar o exercício soberano de controle migratório diante da ameaça ao non-refoulement e aos direitos humanos por ele protegidos. Para tanto, realizou-se pesquisa teórica, bibliográfica e documental, com análise crítico-dogmática dos instrumentos normativos imperativos de direito internacional de proteção aos refugiados, das diretrizes de organizações internacionais e dos precedentes judicias sobre o tema. Em seguida, elaborou-se estudo contextualizado com breve análise de alguns casos recentes de emprego de barreiras fronteiriças como mecanismos de controle migratório. Como norma jus cogens e consuetudinária do direito internacional, o princípio demonstra-se aplicável independentemente de reconhecimento formal do status de refugiado, relativizando a soberania nacional. Apesar da divergência na aplicação do princípio, a imposição de barreiras fronteiriças viola tal princípio, uma vez ser necessário o acesso ao território do Estado de destino para que o processo de determinação da condição de refugiado seja justo e eficaz.

Palavras-chave: Princípio de non-refoulement. Solicitantes de refúgio. Barreiras fronteiriças. Controle migratório. Direitos humanos.

\footnotetext{
*Faculdade de Direito de Ribeirão Preto, Universidade de São Paulo (USP), Ribeirão Preto-SP, Brasil (laisgooli@gmail.com).
} 


\section{Introdução}

A evolução dos meios de transporte facilitou a locomoção de pessoas em busca de refúgio na travessia de fronteiras internacionais, proporcionando, cada vez mais, a movimentação de grandes grupos de refugiados em um curto período de tempo.

Em seu informe anual divulgado em 07 de janeiro de 2015, o Alto Comissariado das Nações Unidas para Refugiados (ACNUR, 2015) relatou que, no primeiro semestre de 2014, cerca de 5,5 milhões de pessoas fugiram de conflitos armados e guerras ocorridos, principalmente, no Oriente Médio e na África, sendo que, desse total, 1,4 milhão de pessoas cruzaram as fronteiras de outros Estados e obtiveram o reconhecimento de seu status de refugiado.

Assim, em razão dessa vultosa movimentação migratória, muitos dos Estados de destino passaram a adotar medidas de contenção migratória nas fronteiras e áreas que lhes dão acesso, escudados pelo princípio da soberania nacional, a fim de proteger seu território. Entretanto, tais fluxos geralmente são compostos por indivíduos em busca de refúgio, cuja proteção contra a recusa fronteiriça é garantida pelo princípio de non-refoulement.

Previsto pelo artigo 33(1) da Convenção de Genebra relativa ao Estatuto dos Refugiados de 1951, o princípio de non-refoulement é imprescindível à proteção internacional dos refugiados e proíbe o Estado de acolhida de aplicar qualquer medida de saída compulsória que encaminhe o refugiado ao território onde sofra, ou possa sofrer, ameaça ou violação aos seus direitos fundamentais em virtude de perseguição, tortura ou tratamentos ou penas cruéis, desumanos ou degradantes, incluindo a proibição de repulsa contra o solicitante de refúgio que intenta permanecer sob a sua jurisdição. 0 princípio tem alcance, portanto, sobre o território do Estado, suas fronteiras e áreas internacionais que lhes dão acesso (LUZ FILHO, 2001).

A priori, tal princípio apenas seria aplicável ao indivíduo que expressamente solicita ao Estado de destino o reconhecimento de sua condição jurídica de refugiado (LUZ FILHO, 2001). Entretanto, a determinação do status de refugiado seria de natureza meramente declaratória, sendo que a pessoa se torna um refugiado por preencher, desde o início de sua fuga, os requisitos para tal definição, conforme artigo 1A(2) da Convenção de Genebra de 1951. Assim, o princípio de non-refoulement também seria aplicável àqueles refugiados que ainda não tiveram seu status formalmente declarado (UNHCR, 2007).

Ademais, a proteção internacional dos refugiados não se efetiva tão somente com o reconhecimento formal do status, mas também com a garantia de acesso às condições que thes permitam solicitar esse reconhecimento às autoridades nacionais, incidindo 0 princípio de non-refoulement nessas duas fases (LUZ FILHO, 2001).

Dessa forma, ao adotar barreiras fronteiriças, o Estado de destino impediria ao refugiado o acesso ao seu território, obstando-o de solicitar o reconhecimento formal de sua condição jurídica e expondo-o ao perigo de permanecer sob a jurisdição do Estado que the ameaça ou viola os direitos humanos, o que implicaria violação do princípio (STOYANOVA, 2008). 
Entretanto, o mencionado artigo 33(1) da Convenção de 1951 não faz menção explícita à aplicação do non-refoulement aos refugiados ainda não reconhecidos formalmente, nem à proibição de sua rejeição na fronteira. Nesse sentido, a prática dos Estados de impor barreiras fronteiriças ao acesso de solicitantes de refúgio envolve a discussão das questões relativas ao âmbito de aplicação de tal princípio e à admissão na fronteira, diante do direito dos Estados soberanos de salvaguardar seus territórios.

Dessa forma, o presente trabalho constitui, primeiramente, uma investigação jurídico-dogmática (GUSTIN, 2010, p. 21), tendo como objeto a análise das estruturas e relações normativas do princípio de non-refoulement, internacionalmente institucionalizado, e dos direitos humanos de refugiados e solicitantes de refúgio, bem como uma investigação jurídico-sociológica (GUSTIN, 2010, p. 22), uma vez que estuda a realização concreta de dito princípio perante as barreiras fronteiriças impostas pelos Estados, compreendendo 0 fenômeno jurídico no ambiente político e sociocultural. Para tanto, fez-se uso das técnicas de pesquisa teórica, nas formas bibliográfica, documental e estatística.

\section{A natureza jurídica do princípio de non-refoulement}

Em sua definição, non-refoulement é um conceito que proíbe os Estados de devolverem um refugiado ou solicitante de refúgio para os territórios em que sua vida ou liberdade, bem como seus demais direitos fundamentais, estejam sob a ameaça de violação por questões de raça, religião, nacionalidade, pertencimento a determinado grupo social ou opinião política (FELLER; NICHOLSON; TÜRK, 2003).

No contexto do direito internacional, o refoulement deve ser compreendido como o gênero abrangente de todas as espécies de institutos jurídicos que visam à saída compulsória do estrangeiro do território nacional - deportação, expulsão, extradição, entre outros -, sendo que a sua essência também inclui a proibição de repulsa do estrangeiro que intenta permanecer sob a jurisdição do Estado de destino, como a rejeição de refugiados ou solicitantes de refúgio nas fronteiras e áreas internacionais que lhe dão acesso (LUZ FILHO, 2001).

Em razão dos diversos contextos em que ganha expressão, o princípio de non-refoulement é identificado como pertencente às três vertentes da proteção internacional da pessoa humana: o direito internacional dos refugiados; ${ }^{1}$ o direito internacional dos direitos humanos; $^{2}$ e o direito internacional humanitário. ${ }^{3}$

\footnotetext{
${ }_{1} 0$ princípio é previsto pela Convenção de Genebra relativa ao Estatuto dos Refugiados de 1951, artigo 33(1), por exemplo.

${ }^{2}$ Conforme dispõem a Convenção Europeia para a Proteção dos Direitos do Homem e das Liberdades Fundamentais, de 1950, artigo 3 (conforme interpretação da Corte Europeia de Direitos Humanos), a Convenção Americana sobre Direitos Humanos, de 1969, artigo 22(8), e a Convenção contra a Tortura e Outras Penas ou Tratamentos Cruéis, Desumanos ou Degradantes, de 1984, artigo 3, por exemplo.

${ }^{3}$ Segundo previsão na Convenção de Genebra relativa à Proteção das Pessoas Civis em Tempo de Guerra (Convenção IV de Genebra), de 1949, artigo 45, por exemplo.
} 
Historicamente, ainda que admitidas algumas situações excepcionais, o desenvolvimento do princípio de non-refoulement demonstraria a verdadeira intenção dos redatores da Convenção de Genebra de 1951 em não permitir que os refugiados ou solicitantes de refúgio sejam rechaçados ou devolvidos, tanto para o seu Estado de origem como para outros territórios onde possam estar em risco (GOODWIN-GILL; MCADAM, 2007).

Contudo, apesar da definição geral acerca do conceito do princípio de non-refoulement em relação aos refugiados, então expressa no artigo 33(1) da referida Convenção de 1951, sua concepção torna-se relevante em diferentes contextos, dependendo da natureza do tratado internacional em que está previsto e da situação específica à qual este se destina (GOODWIN-GILL; MCADAM, 2007).

No que toca à sua natureza jurídica, o mencionado princípio constitui regra de direito internacional de caráter jus cogens, ${ }^{4}$ uma vez reconhecido pela comunidade internacional dos Estados em sua totalidade ${ }^{5}$ como norma não passível de derrogação. ${ }^{6}$ Trata-se, ainda, de norma integrante do direito consuetudinário internacional, ${ }^{7}$ uma vez que a prática dos Estados demonstra sua observância reiterada, com a convicção de que tal ato corresponde à execução de uma obrigação jurídica, admitido certo grau de incompatibilidade (GOODWIN-GILL; MCADAM, 2007; UNHCR, 1994).

\section{0 âmbito de aplicação do princípio de non-refoulement}

A proibição contida no artigo 33(1) da Convenção de Genebra de 1951 corresponde à não transferência, de qualquer forma, do refugiado ou solicitante de refúgio a qualquer território onde ele possa estar em risco, podendo referir-se ao seu país de origem, ou seja, ao país do qual ele supostamente fugiu, ou a qualquer outro país do qual tenha fundado temor de perseguição, tortura, etc. O status legal do território é, todavia, irrelevante (FELLER; NICHOLSON; TÜRK, 2003).

O princípio também se aplica às hipóteses de transferência do refugiado ou solicitante de refúgio para os territórios onde ele possa sofrer um risco direto de ser enviado para

\footnotetext{
$\overline{4}$ Conforme o artigo 53 da Convenção de Viena sobre o Direito dos Tratados, norma de caráter jus cogens é toda norma imperativa de direito internacional geral que for aceita e reconhecida pela comunidade internacional dos Estados no seu conjunto como norma não passível de derrogação e que só pode ser modificada por uma nova norma de direito internacional geral com a mesma natureza.

${ }^{5} \mathrm{O}$ caráter normativo do princípio de non-refoulement, então previsto em diversos instrumentos internacionais, tanto de âmbito universal como regional, e a dimensão da participação dos Estados nesses instrumentos - conforme dados disponibilizados pela ONU - indicam o seu reconhecimento quase universal pela comunidade internacional de Estados, bem como a conduta destes em tentar justificar os casos de devolução pretendida de refugiados como exceções à aplicação do referido princípio, sem se utilizar do argumento de que o direito internacional contemporâneo permitiria o refoulement (COUNCIL OF THE INTERNATIONAL INSTITUTE OF HUMANITARIAN LAW, 2001; UNHCR, 1994).

${ }^{6}$ Por exemplo, tanto o artigo 42(1) da Convenção de Genebra de 1951 como o artigo VII(1) do seu Protocolo de 1967 proíbem a formulação de reservas ao artigo 33 da primeira, afirmando o seu caráter inderrogável (UNHCR, 2007).

${ }^{7}$ Segundo Alberto do Amaral Júnior (2013), para que uma norma seja considerada de direito internacional consuetudinário, são exigidos dois elementos: o elemento material, constituído pela repetição constante e uniforme de determinados atos durante certo período; e o elemento psicológico, isto é, a convicção de que tais atos correspondem à execução de uma obrigação jurídica.
} 
um terceiro território onde haja o perigo de uma subsequente transferência para território onde possa sofrer um risco direto (refoulement indireto) (FELLER; NICHOLSON; TÜRK, 2003) - apesar de permitida a sua transferência para um terceiro Estado seguro (FELLER; NICHOLSON; TÜRK, 2003) -, ou, ainda, em que o refugiado ou solicitante de refúgio encontra-se dentro do seu país ou Estado de origem, mas sob a proteção ou jurisdição de outro Estado (FELLER; NICHOLSON; TÜRK, 2003).

Especificamente acerca do âmbito ratione persona ${ }^{8}$ de aplicação do non-refoulement, este é estendido a todo e qualquer indivíduo que tenha um fundado temor de perseguição, ${ }^{9}$ ou quando houver motivos substanciais para se acreditar que ele estaria sob o risco de tortura, tratamentos ou penas cruéis, desumanos ou degradantes, bem como de violação aos seus direitos humanos, ${ }^{10}$ se devolvido para determinado Estado, independentemente se refugiado formalmente reconhecido ou não, em virtude da natureza meramente declaratória de tal reconhecimento (UNHCR, 2007).

0 artigo 33(2) da Convenção de Genebra de 1951 prevê, todavia, exceções ao âmbito ratione personae de aplicação do princípio. Entretanto, tais exceções devem ser interpretadas restritivamente e apenas serão aplicadas nos casos em que não constituírem ameaça a direitos humanos não derrogáveis, cabendo necessariamente às autoridades do Estado de acolhida julgar, com observância aos requisitos e limitações impostas, bem como ao princípio do devido processo legal, se o indivíduo em questão de fato oferece risco à segurança nacional (FELLER; NICHOLSON; TÜRK, 2003).

Já o âmbito ratione loci $^{11}$ de aplicação do princípio apresenta, primeiramente, um aspecto territorial, por alcançar os refugiados ou solicitantes de refúgio que se encontram no território nacional do Estado de acolhida, ou nos territórios sob o seu controle efetivo (CAT, 2006), e um aspecto extraterritorial, uma vez que a jurisdição do Estado pode ser exercida extraterritorialmente, seja em áreas fronteiriças, em alto mar, em zonas internacionais, em áreas de trânsito, ou até mesmo dentro do território de outro Estado (UNHCR, 2007).

Nesse sentido, o critério decisivo para determinar a obrigação de non-refoulement do Estado de acolhida consiste no fato de o refugiado ou solicitante de refúgio estar sujeito ao controle efetivo e à autoridade do referido Estado (UNHCR, 2007).

\section{A falta de concisão quanto à aplicação do non-refoulement}

Apesar de a interpretação exposta tratar-se do posicionamento oficial do Acnur acerca da interpretação ideal do âmbito de aplicação do princípio de non-refoulement

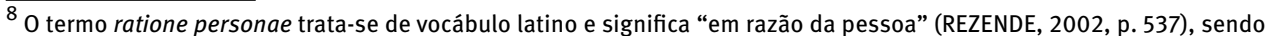
empregado neste trabalho para tratar da aplicação do princípio de non-refoulement em relação à pessoa considerada.

${ }^{9}$ Conforme definição contida no artigo $1 \mathrm{~A}(2)$ da referida Convenção (denominado critério de inclusão), combinada com a disposição do artigo 1(2) do Protocolo de Nova lorque de 1967.

${ }^{10}$ Conforme estabelece o artigo 3 da Convenção contra a Tortura de 1984.

11 Já o vocábulo ratione loci significa "em razão do lugar" (REZENDE, 2002, p. 537) e refere-se ao local onde ocorrerá a aplicação do referido princípio.
} 
- posicionamento adotado pelo presente trabalho -, a sua aplicabilidade ainda não é uniforme na comunidade internacional, uma vez que o conteúdo do referido princípio é composto por termos genéricos e sem uma definição internacional comum, como "perseguição", "tortura" e "tratamento cruel, desumano ou degradante”. Assim, o conceito de non-refoulement mostra-se ambíguo e abstrato (PIRJOLA, 2008), passível de diversas interpretações quanto ao seu âmbito de aplicação.

O non-refoulement contém, portanto, um paradoxo: os Estados estão obrigados a um princípio cujo conteúdo é indeterminado no direito internacional; e a determinação da sua aplicação dependerá da definição do seu conteúdo atribuída pelas autoridades e tribunais, nacionais e internacionais (PIRJOLA, 2008), conforme os valores e interesses envolvidos no caso concreto.

Dessa forma, aliada à imprecisão de conteúdo, a falta de previsão legal internacional de uma interpretação concisa quanto à aplicação do princípio de non-refoulement permite que os Estados adotem abordagens diversas no caso concreto (PIRJOLA, 2008), conforme o que for mais conveniente e adequado para os valores e interesses em contraste - principalmente quando esse princípio contrapõe o direito de exercício de controle migratório pelo Estado.

Ellen D’Angelo (2009) aponta quatro exemplos das diferentes abordagens estatais acerca da implementação do non-refoulement: abordagem da soberania absoluta do Estado; abordagem coletiva ou comunitária; abordagem coletiva ou comunitária distorcida; e abordagem restritiva de definição.

Pela abordagem da soberania absoluta, primeiramente, os Estados entendem o princípio como aplicável apenas no caso de o indivíduo ter cruzado as fronteiras do território do Estado de acolhida com sucesso (D’ANGELO, 2009), prevalecendo o princípio da soberania estatal e o direito de salvaguarda nacional. ${ }^{12}$ No que tange à abordagem coletiva ou comunitária, os Estados têm desenvolvido mecanismos para realocar os refugiados de um Estado para outro, buscando conservar o controle sobre o destino final de tais indivíduos sem, aparentemente, violar o princípio de non-refoulement (D’ANGELO, 2009).

Já a abordagem coletiva ou comunitária distorcida consiste em uma variação da abordagem anterior, por meio da qual os Estados utilizam certas medidas processuais para evitar analisar as solicitações de refúgio e remover os solicitantes de suas fronteiras ${ }^{13}$ (D’ANGELO, 2009). Por fim, a abordagem restritiva de definição assemelha-se à abordagem da soberania absoluta do Estado, utilizando a ambiguidade textual do artigo 33(1) e (2) da Convenção de 1951 para excluir certos indivíduos da proteção contra o refoulement, ainda que já reconhecidos como refugiados nos termos do artigo $1 \mathrm{~A}(2)$ da referida Convenção ${ }^{14}$ (D’ANGELO, 2009).

\footnotetext{
12 Para exemplificar, ver Sale v. Haitians Ctrs. Council (UNITED STATES SUPREME COURT, 1993).

${ }^{13}$ Ver, por exemplo, Case of Amuur v. France (EUROPEAN COURT OF HUMAN RIGHTS, 1996).

${ }^{14}$ Como exemplo, ver INS v. Cardoza-Fonseca (UNITED STATES SUPREME COURT, 1987).
} 
Conforme exposto, essa diversidade de abordagens enfraquece a força vinculante dos instrumentos internacionais que impõem o princípio de non-refoulement e pode levar à supressão desse direito fundamental dos refugiados e solicitantes de refúgio, dificultando a implementação de um regime de proteção efetivo.

\section{A imposição de barreiras fronteiriças pelos Estados diante da proibição de refoulement}

Conforme apresentado anteriormente, muitos Estados de destino de um fluxo constante de imigrantes - incluindo refugiados e solicitantes de refúgio - passaram a empregar medidas para conter a entrada de pessoas por suas fronteiras ou áreas que lhes dão acesso, a título de exercício de regular controle migratório. Seline Trevisanut (2008, p. 207) denomina tais barreiras de "mecanismos de non-entrée".

Helion Póvoa Neto (2007) classifica tais vedações em três categorias: de caráter político-institucional, expressas em políticas migratórias restritivas ao ingresso de migrantes segundo suas qualificações, ou com limitações temporais à sua permanência; de caráter físico, concretizadas em muros, cercas, faixas militarizadas nas fronteiras, zonas minadas do tipo no man's land, ${ }^{15}$ ou as denominadas "territorializações" forçadas, como, por exemplo, campos de confinamento para migrantes, refugiados e solicitantes de refúgio; e de caráter cultural e ideológico, tomando o migrante por alguém inferior, indesejável ou ameaçador à segurança e ao bem-estar da sociedade nacional. Esta última categoria, contudo, não será enfoque do presente trabalho.

Empregadas como exercício regular de controle migratório, tais barreiras representariam a adoção de uma política de classificação social, em que o Estado de destino busca combater o estrangeiro "invasor" com fundamento na defesa da sua coerência econômica, política e socialmente (PÓVOA NETO, 2007). Nesse sentido, o emprego de tais barreiras seria legitimado pela defesa da soberania do Estado, princípio este reconhecido internacionalmente. Esse controle migratório afrontaria, todavia, direitos e garantias de refugiados e solicitantes de refúgio - mais precisamente, o princípio de non-refoulement -, igualmente reconhecidos na seara internacional, demonstrando um aparente conflito entre os dois princípios.

Entretanto, com o advento do sistema internacional das Nações Unidas de proteção dos direitos humanos, a concepção tradicional do princípio da soberania nacional foi relativizada, tanto na esfera internacional como na doméstica, a fim de adequar-se ao referido regime de proteção (MAZZUOLI, 2002). Tal princípio sofreu, portanto, limitações internamente, com o reconhecimento da personalidade internacional do indivíduo (PIOVESAN, 2013), e externamente, com o reconhecimento e a assunção de obrigações de direito internacional pelos próprios Estados (MAZZUOLI, 2002).

\footnotetext{
${ }^{15}$ A expressão em inglês no man's land é literalmente traduzida como "terra de ninguém" e, no contexto empregado, pode tratar-se de uma área desocupada entre as linhas de frente de exércitos inimigos ou de um território desabitado e sem dono (e geralmente indesejável), conforme definição disponível em: 〈http://www.thefreedictionary.com/no+man's+land〉. Acesso em: 31 jul. 2015.
} 
Esse sistema de proteção não derroga, todavia, a noção de soberania estatal, uma vez ser complementar e subsidiário diante da incumbência de garantia pelos Estados (PIOVESAN, 2013). Assim, qualquer abuso deve ser combatido no que diz respeito tanto ao desrespeito à soberania nacional em virtude de uma falsa defesa humanitária (HEE; SOBRINO, 2004), quanto à violação dos direitos humanos - protegidos pelo princípio de non-refoulement, inclusive - pelo abuso no exercício da soberania.

Acerca da não rejeição de solicitantes de refúgio nas fronteiras do Estado de destino, o impacto sofrido por este (GOODWIN-GILL; MCADAM, 2007) em decorrência do influxo em larga escala daqueles indivíduos não ressalva a aplicação do princípio de non-refoulement, visto que, em razão do objetivo humanitário da Convenção de 1951, o conteúdo textual do seu artigo 33(1) não exclui do âmbito de aplicação do princípio tais situações de afluência em massa - a menos que se trate de uma das hipóteses de exceções contidas no parágrafo 2 do mesmo dispositivo (FELLER; NICHOLSON; TÜRK, 2003).

Não obstante, no que toca à entrada e permanência ilegal de solicitantes de refúgio no Estado de destino, uma vez que a ideia de refúgio resulta, propriamente, de uma situação de fuga desses indivíduos para buscar abrigo em outro território, a Convenção de 1951, em seu artigo 31(1), não encara a regularidade da sua entrada e presença no Estado de acolhida como um requisito necessário para sua admissão (GOODWIN-GILL; MCADAM, 2007); pelo contrário, proíbe que lhes sejam aplicadas penalidades ou qualquer tratamento desfavorável por essa razão.

Contudo, em virtude da indefinição de termos contidos no mencionado artigo 31 (GOODWIN-GILL; MCADAM, 2007), como "sanções penais" e "restrições necessárias", a admissão de solicitantes de refúgio nas fronteiras fica a cargo dos Estados de destino, submetendo a aplicação do non-refoulement, novamente, à interpretação discricionária daqueles.

Ademais, com o desenvolvimento do sistema de proteção internacional dos direitos humanos e do direito internacional, de uma forma geral, o conceito do princípio de non-refoulement passou a englobar não apenas a não expulsão de refugiados e solicitantes de refúgio para o seu território de origem, mas também a sua não rejeição nas fronteiras e áreas que lhes dão acesso (GOODWIN-GILL; MCADAM, 2007). Assim, a imposição de mecanismos de non-entrée resulta em automática rejeição do indivíduo que pretende ingressar no território e solicitar o reconhecimento formal de sua condição jurídica de refugiado, consistindo, igualmente, em sua inadmissão indireta.

O non-refoulement não garante, contudo, o direito de reconhecimento jurídico do status, uma vez que essa não rejeição na fronteira implicaria tão somente um direito de admissão temporária, para fins de determinação formal da condição de refugiado, sendo que apenas dessa forma o Estado pode assegurar não retornar o indivíduo para o lugar onde ele possa sofrer perseguição ou tortura (GOODWIN-GILL; MCADAM, 2007).

Outrossim, não é possível haver proteção efetiva contra o refoulement sem o acesso ao território do Estado de destino, uma vez que o procedimento de reconhecimento formal da 
condição de refugiado só pode ser justo e eficaz se conduzido em seu interior (STOYANOVA, 2008). Nesse sentido, reconhece-se que a obrigação de non-refoulement pode equivaler a uma obrigação do Estado de destino em aceitar solicitantes de refúgio em seu território, nos casos em que a negativa de acesso resultar, direta ou indiretamente, em exposição daqueles ao risco de refoulement (STOYANOVA, 2008), ainda que não haja expressão legal internacional de um direito de ingresso. ${ }^{16}$

Consequentemente, a prática dos Estados de impedir esse acesso com vedações fronteiriças viola o princípio de non-refoulement, pois obsta o direito daqueles a um procedimento justo e eficaz de reconhecimento formal de sua condição de refugiados sem o risco de serem devolvidos para o território onde temam sofrer perseguição ou uma violação de direitos humanos, bem como a garantia de não serem devolvidos enquanto perdurar o procedimento.

Percebe-se que o non-refoulement incide nas duas etapas da proteção internacional dos refugiados: assegura ao refugiado formalmente reconhecido a garantia de não ser devolvido para o território onde tenha fundado temor de sofrer perseguição ou violação de direitos humanos; e garante ao solicitante de refúgio a segurança de requerer esse reconhecimento formal sem ser devolvido para tal, bem como de não o ser enquanto perdurar o referido procedimento (LUZ FILHO, 2001).

Não obstante, no que tange ao direito de admissão temporária, apesar de o fenômeno de afluência em massa de pessoas em busca de refúgio comumente resultar na incapacidade dos sistemas nacionais em absorver e processar o número elevado de solicitações simultâneas (GOODWIN-GILL; MCADAM, 2007), a movimentação vultosa não afasta a concessão da proteção temporária, uma vez que esta visa à proteção do solicitante de refúgio contra o refoulement, para que ele busque uma solução duradoura ao seu caso (UNHCR, 2007). Assim, a proteção temporária consiste em uma resposta pragmática que permite a determinação procedimental do status de refugiado e, consequentemente, a aplicação do non-refoulement (GOODWIN-GILL; MCADAM, 2007). Tal medida deve ser aplicada como um mecanismo de rápida resposta humanitária. ${ }^{17}$

Nesse sentido, a imposição de barreiras nas fronteiras do território do Estado de destino, além de impedir o acesso de solicitantes de refúgio aos procedimentos justos e eficazes para a determinação formal da sua condição, também obsta o direito daqueles à proteção temporária, impedindo-os de buscar uma solução duradoura para sua situação, seja o mencionado reconhecimento como refugiado, ou o seu envio a um terceiro Estado seguro onde possam requerê-lo.

\footnotetext{
${ }^{16} 0$ artigo 13(2) combinado com o artigo 14(1), ambos da Declaração Universal dos Direitos Humanos, estabelecem o direito de o indivíduo abandonar o país em que se encontra e buscar e gozar de refúgio em outros países, ou seja, um direito de "saída" de determinado Estado, mas não de "entrada" em outros Estados.

17 Segundo Joan Fitzpatrick (2000 apud GOODWIN-GILL; MCADAM, 2007), a proteção temporária serviria como uma estratégia de curto prazo para garantir a segurança física imediata de refugiados e solicitantes de refúgio, bem como uma etapa para uma solução mais duradoura.
} 
Quanto à aplicação da obrigação de non-refoulement nas hipóteses de adoção de barreiras nas fronteiras marítimas de um Estado costeiro, a Convenção das Nações Unidas sobre o Direito do Mar, de 1982, considera o mar territorial como parte do território do Estado, sobre o qual este também é soberano e exerce jurisdição. ${ }^{18}$ Assim, a observância do non-refoulement quanto à admissão de solicitantes de refúgio no mar territorial do Estado de destino segue o mesmo raciocínio que a admissão daqueles nas fronteiras terrestres: ao menos temporariamente, para fins de acesso a procedimentos justos e eficazes de determinação formal do status de refugiado ou a outra solução duradoura.

Não obstante, ainda que a passagem de embarcações transportando imigrantes com a pretensão de entrar ilegalmente no mar territorial do Estado de destino possa ser considerada não inocente, em virtude da violação à sua legislação doméstica de imigração, ${ }^{19}$ sua passagem não pode ser impedida na hipótese de haver refugiados ou solicitantes de refúgio a bordo, uma vez que o artigo 31(1) da Convenção de 1951 proíbe a penalização de solicitantes de refúgio que entram ou permanecem de forma irregular no Estado de destino. Ademais, em vista da relativização do princípio da soberania estatal, o direito de controle sobre o mar territorial é limitado pela observância da obrigação de non-refoulement.

Outrossim, não é possível haver proteção efetiva contra o refoulement sem o acesso aos portos de desembarque do Estado de destino e, consequentemente, ao seu território, uma vez que o procedimento de reconhecimento formal da condição de refugiado só pode ser justo e eficaz se conduzido no interior do território. Já no caso de solicitantes de refúgio passageiros clandestinos, não há, todavia, norma internacional vigente que regulamente a questão do seu desembarque. ${ }^{20}$

Nesse caso, apesar de o Estado portuário de destino não ser obrigado internacionalmente a autorizar tal desembarque (TREVISANUT, 2008), o Acnur entende que aquele pode, sem violar o princípio de non-refoulement: exigir que o comandante do navio mantenha o solicitante clandestino a bordo e viaje para o próximo porto de escala; invocar o Estado sob cuja bandeira o navio trafega para que este assuma a responsabilidade sobre o solicitante clandestino, no caso do próximo porto de escala ser inaceitável; ou permitir o seu desembarque temporário, pendente o seu reassentamento em outro lugar (GOODWIN-GILL; MCADAM, 2007). Nesta última hipótese, entretanto, o Estado costeiro deve garantir que o novo Estado de destino seja seguro para aquele solicitante (TREVISANUT, 2008).

Já no caso das zonas marítimas contíguas ao mar territorial, sua função para o Estado costeiro é tanto preventiva como repressiva, sendo que a Convenção sobre o Direito do Mar de 1982 permite-lhe o exercício de controle migratório sobre elas (TREVISANUT, 2008). Entretanto, o exercício da soberania do Estado na zona contígua é limitado pelo critério da

\footnotetext{
$\overline{18}$ Conforme artigo 2(1), (2) e (3) da mencionada Convenção.

${ }^{19}$ Nos termos do artigo 19(2)(g) da mesma Convenção.

${ }^{20}$ A Convenção Internacional relativa aos Passageiros Clandestinos (“Convenção de Bruxelas”), de 1957, define "passageiro clandestino" como uma pessoa que, em qualquer porto ou lugar de sua proximidade, se oculta em um navio, sem o consentimento do proprietário, do comandante, ou de qualquer outra pessoa no comando do navio e que se encontra a bordo, após o navio ter deixado aquele porto ou lugar. Essa Convenção, todavia, nunca entrou em vigor (UNHCR, 1957).
} 
"necessidade" da medida a ser tomada ${ }^{21}$ e, principalmente, pela observância do princípio de non-refoulement. Assim, ao exercer seu poder de controle migratório interceptando e redirecionando um navio nessa zona, o Estado deve considerar se tal ato colocará os passageiros em risco de refoulement, ainda que desrespeitadas suas normas internas de migração (TREVISANUT, 2008).

Por fim, quanto ao exercício de controle migratório em alto mar, apesar de nele vigorar o princípio da liberdade de navegação, ${ }^{22}$ este é limitado pelo princípio de salvaguarda da vida humana, ${ }^{23}$ do qual decorre o dever de prestar assistência a qualquer pessoa ou embarcação em perigo no mar - a ser observado em todas as diferentes zonas marítimas (TREVISANUT, 2008).

Entretanto, esse dever de assistência só é plenamente cumprido após o desembarque dos resgatados em um lugar seguro (UNHCR, 2002), sendo que, no caso de resgate de refugiados ou solicitantes de refúgio no mar, o desembarque seguro corresponde à observância do princípio de non-refoulement (TREVISANUT, 2008). Conforme posicionamento do Acnur, esse desembarque deve ocorrer no território costeiro mais próximo ao local de salvamento (GOODWIN-GILL; MCADAM, 2007).

Já no que toca à admissão dos solicitantes de refúgio resgatados em alto mar, ainda que temporariamente, e à garantia do acesso aos procedimentos justos e eficazes de refúgio, o Acnur atribui, aos Estados costeiros mais próximos da área de resgate, a responsabilidade de aceitar seu desembarque e de oferecer-lhes uma proteção temporária, para permitir o acesso a procedimentos justos e eficazes de determinação do seu status, ou a outra solução duradoura (UNHCR, 2002), em respeito ao non-refoulement.

Contudo, essa responsabilidade atribuída ao Estado costeiro mais próximo enseja aos Estados de destino de um fluxo constante de solicitantes de refúgio a adoção de programas de salvamento em alto mar como um disfarce para políticas de interceptação de embarcações como controle migratório. Tais políticas operam como mecanismos indiretos de non-entrée, obstando o acesso ao território - já que não há uma definição legal precisa do que constituiria um "perigo" no mar (GAMMELTOFT-HANSEN, 2011).

Nesse sentido, a prática de interceptação viola o princípio de non-refoulement e, inclusive, o direito dos solicitantes de refúgio resgatados no mar de buscar proteção (GOODWIN-GILL; MCADAM, 2007), pois funciona como barreira ao acesso ao território do Estado de destino, ou de qualquer outro Estado seguro, impedindo seu acesso a procedimentos justos e eficazes de determinação de seu status e os expondo, ainda, ao perigo de serem forçadamente redirecionados para um território onde sua vida, integridade física e liberdade sejam ameaçadas.

\footnotetext{
${ }^{21}$ Conforme artigo 33(1) da Convenção sobre o Direito do Mar de 1982.

${ }^{22}$ Artigo 87(1)(a) da Convenção sobre o Direito do Mar de 1982.

${ }^{23}$ Nesse sentido foram adotadas a Convenção Internacional para a Salvaguarda da Vida Humana no Mar, de 1974, e o seu Protocolo relativo, de 1988, a Convenção Internacional sobre Busca e Salvamento Marítimo, de 1979, e a Convenção Internacional sobre Salvamento Marítimo, de 1989.
} 
Ademais, acerca da prática de interceptação em alto mar, qualquer medida de intervenção em alto mar implica, por meio do ato em si mesmo, exercício de jurisdição pelo Estado interventor e, consequentemente, uma obrigação em nome deste de respeitar direitos básicos, nos termos dos direitos internacionais dos direitos humanos e dos refugiados, ainda que não equivalha ao controle efetivo sobre indivíduos ou certa área geográfica (GAMMELTOFT-HANSEN, 2011).

Dessa forma, em razão do âmbito extraterritorial de aplicação do non-refoulement, este se aplica independentemente se a ação do Estado interceptor ocorreu ou não fora do seu território nacional (GOODWIN-GILL; MCADAM, 2007), podendo ensejar a responsabilização internacional desse Estado.

\section{Breve análise de casos recentes de emprego de barreiras fronteiriças}

Primeiramente, conforme anunciado no início de janeiro de 2015, o governo libanês passou a exigir determinados critérios para a concessão de vistos de entrada a nacionais sírios, exclusivamente, impondo novas modalidades de autorização com prazos limitados, a fim de conter o fluxo migratório (BBC, 2015).

Isso porque, segundo informe anual do Acnur, até meados de 2014 a Síria tornou-se o maior país fonte de pessoas sob a proteção internacional do referido órgão, tendo sido registrados mais de 3 milhões de refugiados sírios no período mencionado, correspondendo a $23 \%$ de todos os refugiados sob o mandato do Acnur (UNHCR, 2014, p. 04). Ademais, até maio de 2015, o Líbano já teria assumido cerca de 1,1 milhão de refugiados sírios. ${ }^{24}$

Assim, com 257 refugiados para cada mil habitantes na época, o Líbano permanecia como o país com a maior densidade de refugiados em meados de 2014 (UNHCR, 2014, p. 04 e 07). Não obstante, o maior número de chegadas de novos refugiados durante o mesmo período foi notificado pelo Líbano, aproximadamente $324.900^{25}$ (UNHCR, 2014, p. 07).

Entretanto, apesar do engajamento do país em relação à crise síria e do grande impacto por ele sofrido em razão dessa movimentação em massa (UNHCR, 2014), tal situação não afasta a aplicação do princípio de non-refoulement, uma vez que aos solicitantes de refúgio em situação de influxo maciço deve ser oferecida, ao menos, proteção temporária, a fim de que possam solicitar o reconhecimento formal do seu status de refugiados ou buscar outra solução de caráter duradouro.

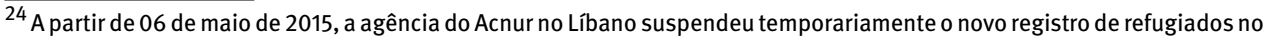
país, por instruções do próprio governo libanês. Assim, o número oficial atual de refugiados sírios devidamente registrados no Líbano é de 1.172.753, não sendo incluídos os indivíduos que aguardam para serem registrados, conforme informação disponibilizada em: 〈http://data.unhcr.org/syrianrefugees/country.php?id=122〉. Acesso em: 24 jul. 2015. Além do registro oficial, estima-se que o número real de sírios no Líbano seria por volta de 1,6 milhão (BBC, 2015).

${ }^{25}$ Conforme o Acnur, a expectativa é de que o Líbano ainda tenha recebido cerca de 1,3 milhão de refugiados sírios no início de 2015 (UNHCR, 2014, p.01).
} 
Além disso, ao se direcionar especificamente aos nacionais sírios, a medida libanesa ainda se mostra discriminatória, visto que a proteção temporária deve ser oferecida sem qualquer discriminação de raça, religião, opinião política, nacionalidade, país de origem ou incapacidade física.

Ademais, a obrigação internacional de non-refoulement também engloba o sentido de admissão - ainda que temporária - e não rejeição na fronteira, sendo imprescindível o acesso ao território do Estado de acolhida para a proteção efetiva contra o refoulement, já que o procedimento de determinação da condição de refugiado só pode ser justo e eficaz se conduzido no interior do território do Estado de destino.

Por essa razão, a nova medida imigratória libanesa funcionaria como um mecanismo político-institucional de non-entrée, dificultando - senão impedindo - o acesso de refugiados e solicitantes de refúgio ao território libanês e violando, portanto, o princípio de non-refoulement.

Apesar de não ser signatário da Convenção de Genebra de 1951 (UNITED NATIONS TREATY COLLECTION, 1951), o Líbano é signatário de outros instrumentos internacionais que preveem o non-refoulement, além do caráter de norma de direito internacional consuetudinário do princípio, que o torna obrigatório independentemente de qualquer vínculo convencional.

Essa conclusão decorre, obviamente, da interpretação e aplicação adotada pelo Acnur acerca do referido princípio, ou seja, condizente com o atual sistema internacional de proteção dos direitos humanos e dos refugiados.

Entretanto, tendo em vista que a falta de previsão legal na esfera internacional de uma interpretação concisa acerca do âmbito de aplicação de dito princípio, aliada à imprecisão de seu conteúdo, pode permitir ao Líbano a adoção de uma abordagem diversa da defendida pelo presente trabalho, conforme o seu interesse prioritário em preservar a integridade e a estabilidade do país, o exercício desse tipo de controle imigratório poderia não ensejar responsabilização do país por eventual violação ao non-refoulement.

Ademais, ao avaliar a atuação libanesa quanto à promoção de direitos humanos, em 2015, o Grupo de Trabalho sobre o Exame Periódico Universal do Conselho de Direitos Humanos da ONU não fez qualquer menção à referida política imigratória, sendo que a maioria das delegações dos Estados-membros teria elogiado o país por sua atuação em relação à questão dos refugiados no país (CONSEJO DE DERECHOS HUMANOS, 2015). ${ }^{26}$

Não obstante, em dezembro de 2012, o governo grego finalizou a construção de uma cerca metálica junto à fronteira terrestre do país com a Turquia, juntamente com a introdução de um sistema de vigilância eletrônica (UNHCR, 2014), a fim de proteger as fronteiras orientais externas da União Europeia (UE) e preservar o livre trânsito de pessoas entre os países integrantes do Espaço Schengen (UNHCR, 2014).

\footnotetext{
${ }^{26}$ Tal omissão poderia indicar que a medida adotada pelo Líbano não teria resultado em uma restrição concreta ao acesso de refugiados ou solicitantes de refúgios sírios ao país, mas uma suposição dessa natureza demandaria uma análise específica e mais aprofundada do caso.
} 
Ressalta-se que a UE considera o controle das fronteiras externas uma questão de interesse nacional e do bloco como um todo, uma vez que tal controle seria necessário à manutenção e preservação do Espaço Schengen, isto é, da área de livre circulação de pessoas no interior do bloco (EUROPEAN COMMISSION, 2013).

As disposições do referido acordo suprimem o controle nas fronteiras internas da UE, enquanto enrijecem o controle nas fronteiras externas, em conformidade com um único conjunto de regras - o Regulamento de Dublim II (EUROPEAN COMISSION, 2013).

Nesse sentido, conforme observou o Acnur, a Grécia é responsável por gerir uma parte importante das fronteiras externas terrestres e marítimas da UE e do próprio Espaço Schengen, uma vez ser a principal porta de entrada para migrantes no território europeu (UNHCR, 2014, p.06).

Adotando a mesma linha de posicionamento do Acnur, a Corte Europeia de Direitos Humanos já decidiu pela suspensão dessas transferências impostas pelo sistema de Dublin, visando, por um lado, que os Estados-membros cujos sistemas de refúgio já estejam sobrecarregados não sejam colocados sob uma maior pressão e, por outro, que os solicitantes de refúgio não sejam transferidos para os Estados-membros que não podem oferecer-lhes um nível de proteção suficiente (EUROPEAN COURT OF HUMAN RIGHTS, 2011). Isso porque a Corte reconheceu o tratamento degradante e desumano sofrido pelos solicitantes de refúgio na Grécia, decorrente da situação precária que o país enfrenta (EUROPEAN COURT OF HUMAN RIGHTS, 2011).

Contudo, apesar da falta de capacidade econômica e estrutural da Grécia para cumprir com as normas europeias de concessão de refúgio nessa situação de afluência em massa (KAKISSIS, 2011), a imposição de tal cerca mostra-se como uma barreira física ao acesso de pessoas em busca de refúgio, resultando em sua rejeição automática e lhes impedindo o acesso a procedimentos justos e eficazes de determinação formal do seu status, ou a possibilidade de alcançarem outra solução duradoura.

A referida cerca funcionaria, portanto, como um verdadeiro mecanismo físico de non-entrée sob a forma de uma política de controle imigratório sobre as fronteiras externas do Espaço Schengen, impedindo indiscriminadamente o acesso ao território grego e violando, consequentemente, o princípio de non-refoulement.

Entretanto, ao avaliar a atuação grega quanto à promoção de direitos humanos no período de 2015, o Grupo de Trabalho sobre o Exame Periódico Universal do Conselho de Direitos Humanos da ONU também não mencionou o emprego da cerca fronteiriça, sendo que alguns Estados-membros reconheceram o esforço do país quanto à recepção do elevado número de solicitantes de refúgio e apontaram a necessidade de divisão dos encargos, principalmente entre os países-membros do bloco europeu (CONSEJO DE DERECHOS HUMANOS, 2016).

Semelhante ao caso grego, em setembro de 2014, o governo búlgaro concluiu a construção de uma cerca também em sua fronteira terrestre com a Turquia (LYMAN, 2015), com planos de aumentá-la (UNHCR, 2015), tendo os mesmos objetivos que a cerca grega - com a 
diferença de que a Bulgária ainda se encontra em processo de adesão ao Espaço Schengen (EUROPEAN COMMISSION, 2013) e é o país mais pobre do bloco. ${ }^{27}$

Desde a instalação da cerca grega, em 2012, o fluxo de refugiados e solicitantes de refúgio proveniente da Turquia voltou-se para a Bulgária e, segundo relatório do Acnur, o número de solicitantes de refúgio que chegaram ao país teria começado a aumentar em meados de 2013 (UNHCR, 2014).

Assim como a Grécia, a Bulgária está localizada na fronteira oriental do continente europeu e também responde por uma parte importante das fronteiras externas terrestres e marítimas da EU, na qual foi admitida em $2007:{ }^{28}$ seu território representa igualmente uma porta de entrada para o território europeu.

Ademais, por encontrar-se ainda em processo de adesão ao Espaço Schengen (EUROPEAN COMISSION, 2013), o governo búlgaro deve cumprir com as pré-condições exigidas para tanto, isto é, basicamente exercer de forma uniforme o controle sobre as fronteiras externas da área Schengen. Segundo noticiou o Acnur, os esforços para reduzir o número de chegadas irregulares e solicitantes de refúgio na Bulgária tiveram um efeito significativo em 2014, com quase $50 \%$ menos ingressos do que no ano anterior (UNHCR, 2015).

Nesse sentido, a cerca búlgara trata-se também de uma barreira física ao acesso de solicitantes de refúgio ao território, operando como um mecanismo de non-entrée e violando, portanto, o princípio de non-refoulement, feitas as mesmas considerações em relação à cerca grega.

Entretanto, o Grupo de Trabalho sobre o Exame Periódico Universal do Conselho de Direitos Humanos da ONU igualmente não mencionou o emprego da barreira fronteiriça quando da avaliação da atuação búlgara em 2015, tendo sido destacada a questão da xenofobia em relação aos refugiados no país (CONSEJO DE DERECHOS HUMANOS, 2016).

Ainda no continente europeu, em agosto de 2015, o governo húngaro anunciou o término da instalação de uma cerca na fronteira do país com a Sérvia $(G 1,2015)$, a fim de evitar o fluxo de solicitantes de refúgio que utilizam a rota dos Bálcãs para alcançar o norte e o ocidente europeus (BACCHI, 2015). Em fevereiro de 2017, o país anunciou a construção de uma nova cerca, na mesma região, objetivando reforçar a barreira já existente (ESTADÃO, 2017).

Entretanto, tal barreira fronteiriça consiste em uma das inúmeras medidas adotadas pelo governo húngaro para evitar o acesso de pessoas em busca de refúgio ao território do país - e também cumprir com as obrigações decorrentes do Acordo Schengen -, dentre as quais estão a operacionalização de zonas de trânsito nas fronteiras do país com a Croácia, em 2015, com a detenção de solicitantes de refúgio, e, inclusive, a tipificação dos crimes de travessia não autorizada da cerca de fronteira, depredação da cerca de fronteira e obstrução das obras de construção relacionadas com a cerca fronteiriça (UNHCR, 2016).

\footnotetext{
${ }^{27}$ Conforme informações disponibilizadas em: 〈http://www.heritage.org/index/country/bulgaria〉. Acesso em: 27 jul. 2015.

28 Conforme dados disponibilizados pela própria UE. Disponível em: 〈http://europa.eu/about-eu/countries/membercountries/bulgaria/index_pt.htm>. Acesso em: 27 jul. 2015.
} 
Observa-se que o emprego da referida cerca, aliado às outras espécies de barreiras fronteiriças adotadas, funciona como mecanismo de non-entrée em relação às pessoas em busca de refúgio, e suas consequências são as mesmas já verificadas quanto às cercas grega e búlgara.

Ressalta-se que, em 2012, o Acnur já havia advertido a Hungria para garantir o acesso ao território do país aos solicitantes de refúgio, em respeito ao princípio de non-refoulement, e para assegurar o pleno acesso ao processo de refúgio em todos os contextos (UNHCR, 2012).

Em 2016, foram feitas recomendações ao país acerca da necessidade de evitar o rechaço e a discriminação de refugiados, inclusive nas fronteiras, conforme resultado da avaliação do Grupo de Trabalho sobre o Exame Periódico Universal do Conselho de Direitos Humanos da ONU (CONSEJO DE DERECHOS HUMANOS, 2016).

Por fim, no que tange à América Latina, ainda que seja reconhecida internacionalmente pelas práticas legislativas inovadoras, de acolhida e de não rejeição fronteiriça de refugiados e solicitantes de refúgio (ACNUR, [2014-2016]; CONARE; UNHCR, 2010; LAVANCHY, 2004; MOREIRA, 2005), destaca-se caso brasileiro recente de imposição de barreiras física e político-institucionais a solicitantes de refúgio.

Ao final de setembro de 2016, cerca de 30 solicitantes de refúgio, com documentação e situação migratória regular no Brasil, foram retidos pela Polícia Federal no Espaço Conector do Aeroporto Internacional de Guarulhos, em São Paulo (MIGRAMUNDO, 2016). Apesar de apresentarem autorização de saída e retorno ao Brasil, em observância ao artigo 13 da Resolução Normativa nํ18/2014 do Comitê Nacional para os Refugiados (Conare) (CGARE; CONARE, 2014, p. 4), tais indivíduos teriam sido impedidos de ingressar oficialmente em território brasileiro (MIGRAMUNDO, 2016).

Segundo a Nota Informativa 09/2016, da Divisão de Polícia de Imigração, emitida em 21 de setembro de 2016 e editada a partir da Resolução Normativa no 23/2016 do Conare (2016), o artigo 13 da Resolução Normativa no 18/2014 foi revogado e ao solicitante de refúgio que viajasse ao exterior passou a ser aplicado o regime de exigência de vistos vigente no país.

Em vista da negativa de acesso ao território, os solicitantes de refúgio barrados foram mantidos isolados no Espaço Conector do Aeroporto Internacional de Guarulhos, em São Paulo, pela Polícia Federal (MIGRAMUNDO, 2016). Referido espaço consiste em uma sala relativamente pequena, entre os setores de desembarque e de imigração do Terminal 3 do aeroporto, sem condições apropriadas para a permanência de pessoas por um longo período (CONECTAS DIREITOS HUMANOS, 2014; MIGRAMUNDO, 2016), a qual perde a função de "sala de espera" e passa a ser utilizada como uma forma de "territorialização" forçada (PÓVOA NETO, 2007).

Observa-se que a imposição de tais barreiras político-institucionais e físicas aos solicitantes de refúgio funcionam como mecanismo de non-entrée, sendo que suas consequências são as mesmas já verificadas nos casos europeus abordados anteriormente. 
Não obstante, tais medidas restritivas ainda violam o $\$ 2^{\circ}$ do artigo $2^{\circ}$ da Resolução no 18/2014 do Conare, segundo o qual o simples protocolo de solicitação de refúgio já confere ao seu titular os direitos assegurados pela lei nacional de refúgio (Lei n. 9.474/1997), pela Constituição Federal de 1988 e pelas convenções internacionais atinentes ao tema, bem como os mesmos direitos inerentes aos estrangeiros em situação regular em território nacional, até o trânsito em julgado do procedimento administrativo (CGARE; CONARE, 2014, p. 4).

Entretanto, o Ministério da Justiça permitiu o ingresso de tais indivíduos após verificar que o novo regramento criava novos entraves jurídicos aos solicitantes de refúgio, além do fato de que ele não poderia ser aplicado a pessoas que haviam recebido autorização de saída do país antes da edição da referida normativa (MIGRAMUNDO, 2016). Ressalta-se, ainda, que a própria Resolução Normativa no 23/2016 do Conare estabelece em seu artigo 7ํㅡㄹ parágrafo único, que a condição de refúgio não obstaculizará a concessão de visto de entrada no país (CONARE, 2016).

\section{Conclusões}

0 caráter de norma consuetudinária de direito internacional do princípio de non-refoulement e a sua natureza de jus cogens tornam-lhe aplicável a todos os entes da comunidade internacional, independentemente de vinculação por convenções ou tratados, o que possibilita a responsabilização internacional de qualquer Estado ou organização internacional que viole dito princípio.

Ademais, a natureza meramente declaratória do non-refoulement evidencia sua aplicação tanto aos refugiados formalmente reconhecidos como aos solicitantes de refúgio, individuais ou em situação de influxo em larga escala, ainda que estes não tenham expressamente solicitado a determinação de seu status, uma vez já existir situação fática de refúgio.

Nesse sentido, o impedimento do acesso de solicitantes de refúgio ao território do Estado de destino, por meio do emprego de mecanismos fronteiriços de non-entrée, viola o princípio de non-refoulement, pois obsta o direito conferido àqueles de ter acesso a procedimentos justos e eficazes de reconhecimento formal do seu status, sem o risco de serem devolvidos ao território onde sofram ou temam sofrer perseguição ou violação à sua vida, integridade física ou liberdade, bem como a garantia de não o ser enquanto perdurar referido procedimento.

Além disso, uma vez que tais procedimentos só podem ser justos e eficazes se conduzidos no interior do Estado de destino, a proteção contra o refoulement só é efetiva com o acesso do solicitante de refúgio ao território. Nesse sentido, em determinados casos o princípio de non-refoulement pode equivaler a uma obrigação do Estado de destino de aceitá-los em seu território, ainda que não haja expressão legal internacional de um direito de entrada.

Conclui-se, portanto, que o simples óbice ao acesso a procedimentos justos e eficazes de determinação do status de refugiado já viola o princípio de non-refouelement e, 
consequentemente, faz do impedimento de acesso ao território do Estado de destino o meio de violação.

Não obstante, o conceito de non-refoulement engloba não apenas a não expulsão de refugiados e solicitantes de refúgio para o território de origem, mas também a sua não rejeição nas fronteiras e áreas de acesso ao Estado de destino. A imposição de barreiras nessas áreas resulta em automática rejeição da pessoa em busca de refúgio, consistindo, igualmente, em sua inadmissão indireta.

0 rechaço do refugiado ou solicitante de refúgio nas fronteiras, nas demais áreas internacionais que dão acesso ao território do Estado de acolhida, ou mesmo no território de outro Estado configura, portanto, violação ao princípio de non-refoulement, uma vez que o critério decisivo para determinar tal obrigação consiste no fato de o refugiado ou solicitante de refúgio estar sob o controle efetivo e a autoridade do Estado em questão, ainda que em exercício extraterritorial de jurisdição.

0 non-refoulement, contudo, não garante o direito de reconhecimento jurídico do indivíduo como refugiado, mas sim o direito de acesso temporário ao território para fins de determinação do seu status, ou de busca de outra solução duradoura.

Conforme exposto, o princípio aplica-se aos casos recentes apresentados, independentemente do Líbano, da Grécia, da Bulgária e da Hungria serem ou não signatários dos instrumentos convencionais internacionais que preveem o non-refoulement, uma vez que este se trata de norma imperativa de direito internacional consuetudinário.

No caso libanês, apesar da iminente crise humanitária no país, a medida restritiva impede que solicitantes de refúgio ingressem no seu território e sejam admitidos, ainda que temporariamente, para ter acesso a um procedimento justo e eficaz de determinação do seu status, violando, portanto, dito princípio.

Já nos casos grego, búlgaro e húngaro, todas as barreiras têm por finalidade conter o fluxo em massa de solicitantes de refúgio que se direcionam aos seus respectivos territórios, não apenas para não comprometer suas estabilidades internas, mas também para exercer controle migratório nas fronteiras externas do Espaço Schengen e preservar a segurança dos Estados participantes da área. Assim, tais barreiras impedem o acesso de solicitantes de refúgio ao território dos referidos Estados e a um procedimento justo e eficaz de reconhecimento da sua condição jurídica de refugiado, em violação ao non-refoulement.

No caso brasileiro, por sua vez, o condicionamento do retorno de solicitantes de refúgio já documentados e autorizados a deixar o país à concessão de visto, bem como a sua manutenção em espécie de "territorialização" forçada, objetivou a contenção de pessoas de ingresso "não autorizado", violando o princípio de non-refoulement nas mesmas condições que os demais casos apresentados.

Contudo, a imprecisão do conteúdo do princípio de non-refoulement e a falta de uma interpretação uniforme sobre ele, legalmente prevista na seara internacional, proporcionam a cada Estado um grande poder discricionário quando da interpretação e aplicação do princípio. 
Nesse sentido, a fim de assegurar a aplicação do non-refoulement conforme exposto, um caminho possível seria definir expressamente o seu conteúdo e abrangência no âmbito do direito internacional - mas sem a presunção (ingênua) de que a legalização do direito apresentado afastaria por completo as práticas violadoras dos Estados.

\section{Referências}

ACNUR - Alto Comisionado de las Naciones Unidas para los Refugiados. Buena Práctica 3: la legislación nacional prescribe que no se rechazará en frontera al solicitante y que no se le penalizará por entrada o presencia ilegales. Protección de Refugiados en América Latina: Buenas Prácticas Legislativas. Disponível em: 〈http://www.acnur.org/que-hace/proteccion/proteccionde-refugiados-en-america-latina-buenas-practicas-legislativas/〉. Acesso em: 26 mar. 2017.

AMARAL JÚNIOR, A. do. Curso de Direito Internacional Público. 4. ed. São Paulo: Atlas, 2013.

BACCHI, U. Migrant crisis: Hungary planning border fence to keep refugees out. International Business Times, 17 Jun. 2015. Disponível em: 〈http://www.ibtimes.co.uk/migrant-crisis-hungaryplanning-border-fence-keep-refugees-out-1506655>. Acesso em: 28 jul. 2015.

BBC NEWS. Syrians entering Lebanon face new restrictions, 05 Jan. 2015. Disponível em: 〈http:// www.bbc.com/news/world-middle-east-30657003〉. Acesso em: 24 jul. 2015.

CAT - United Nations Committee Against Torture. Consideration of reports submitted by States Parties under article 19 of the Convention against Torture and Other Cruel, Inhuman or Degrading Treatment or Punishment, 25 July 2006. Disponivel em: 〈http://www.refworld.org/ docid/453776c60.html.. Acesso em: 06 jan. 2015.

CONARE - Comitê Nacional para os Refugiados. Resolução Normativa no 23 de 30 de setembro de 2016. Estabelece procedimentos de solicitação de passaporte e viagem ao exterior para pessoas refugiadas e solicitantes de refúgio. Brasília: Ministério da Justiça e Cidadania, 2016. Disponivel em: 〈https://www.legisweb.com.br/legislacao/?id=333646〉. Acesso em: 08 jun. 2017.

CONARE - Comitê Nacional para os Refugiados; CGARE - Coordenação-Geral de Assuntos de Refugiados. Resolução Normativa no 18, de 30 de abril de 2014. Estabelece os procedimentos aplicáveis ao pedido e tramitação da solicitação refúgio e dá outras providências. Brasília: Ministério da Justiça, 2014. Disponível em: 〈http://www.justica.gov.br/seus-direitos/ estrangeiros/refugio/anexos/resolucao-18-dou-pdf.pdf〉. Acesso em: 29 abr. 2016.

CONECTAS DIREITOS HUMANOS. Migrantes em Guarulhos. 18 dez. 2014. Disponivel em: 〈http:// www.conectas.org/pt/acoes/politica-externa/noticia/27625-migrantes-em-guarulhos`. Acesso em: 08 jun. 2017.

CONSEJO DE DERECHOS HUMANOS DE LAS NACIONES UNIDAS. Informe del Grupo de Trabajo sobre el Examen Periódico Universal - Bulgaria. [S.I.], 08 de julio de 2015. UN doc. A/HRC/30/10. Disponivel em: «https://documents-dds-ny.un.org/doc/UNDOC/GEN/G15/151/93/PDF/G1515193. pdf?OpenElement>. Acesso em: 26 mar. 2017.

Informe del Grupo de Trabajo sobre el Examen Periódico Universal - Grecia. [S.I.], 08 de julio de 2016. UN doc. A/HRC/33/7. Disponivel em: 〈https://documents-dds-ny.un.org/ doc/UNDOC/GEN/G16/146/48/PDF/G1614648.pdf?OpenElement>. Acesso em: 26 mar. 2017.

Informe del Grupo de Trabajo sobre el Examen Periódico Universal - Hungría. [S.I.], 08 de julio de 2016. UN doc. A/HRC/33/9. Disponivel em: 〈https://documents-dds-ny.un.org/ doc/UNDOC/GEN/G16/146/60/PDF/G1614660.pdf?OpenElement>. Acesso em: 26 mar. 2017. 
. Informe del Grupo de Trabajo sobre el Examen Periódico Universal - Líbano. [S.I.], 22 de diciembre de 2015. UN doc. A/HRC/31/5 Disponível em: <https://documents-dds-ny.un.org/ doc/UNDOC/GEN/G15/289/58/PDF/G1528958.pdf?OpenElement>. Acesso em: 26 mar. 2017.

COUNCIL OF THE INTERNATIONAL INSTITUTE OF HUMANITARIAN LAW. San Remo Declaration on the Principle of Non-Refoulement. Twenty-Fifth Round Table. San Remo, 6-8 September 2001. Disponivel em: 〈http://webcache.googleusercontent.com/search?q=cache:bAG7FdSr7LA):www. iihl.org/iihl/Album/San\%2520Remo\%2520Declaration\%2520\%2520on\%2520the\%2520Prin ciple $\% 2520$ of\% 2520 Non-Refoulement.doc $+\& c d=1 \& h l=p t-B R \& c t=c l n k \& g l=b r r$. Acesso em: 28 dez. 2014.

D'ANGELO, E. F. Non-refoulement: the search for a consistent interpretation of article 33. Vanderbilt Journal of Transnational Law, v. 42, n. 79, p. 279-315, 2009. Disponivel em: 〈http:// www.vanderbilt.edu/jotl/manage/wp-content/uploads/DAngelo-final_x.pdf>. Acesso em: 12 jan. 2015.

ESTADÃO. Hungria inicia construção de nova cerca na fronteira com Sérvia para barrar refugiados. 27 fev. 2017. Disponível em: 〈http://internacional.estadao.com.br/noticias/geral, hungria-iniciaconstrucao-de-nova-cerca-na-fronteira-com-servia-para-barrar-refugiados,70001681187 $>$. Acesso em: 26 mar. 2017.

EUROPEAN COMMISSION. Schengen Area. Migrations and home affairs, what we do, policies. [S.l.], 2013. Disponivel em: 〈http://ec.europa.eu/dgs/home-affairs/what-we-do/policies/ borders-and-visas/schengen/index_en.htm>. Acesso em: 26 jul. 2015.

EUROPEAN COURT OF HUMAN RIGHTS. Case of Amuur v. France. Reports of judgments (Meritsand Just Satisfaction). Strasbourg, 26 June 1996. Disponivel em: 〈http://hudoc.echr.coe.int/sites/ eng/pages/search.aspx?i=001-57988\#\{“itemid”:[“001-57988”]\}>. Acesso em: 14 jan. 2015.

. Case of M.S.S.v. Belgium and Greece. Reports of Judgments and Decisions. Strasbourg, 21 January 2011. Disponivel em: 〈http://hudoc.echr.coe.int/eng?i=001-103050\#\{“itemid”: [“001-103050”]\}>. Acesso em: 26 jul. 2015.

FEDERAL COURT OF APPEAL OF CANADA. Thabet v. Canada (Minister of Citizenship and Immigration), (C.A.), [1998] 4 F.C. 21, Ottawa, 11 May 1998. Doc. A-20-96. Disponivel em: 〈http:// reports.fja.gc.ca/eng/1998/1998fc22467.html). Acesso em: 13 jan. 2015.

FELLER, E.; NICHOLSON, F.; TÜRK, V. Refugee protection in international law: UNHCR's Global Consultations on International Protection. Cambridge: Cambridge University Press, 2003.

GAMMELTOFT-HANSEN, T. Access to asylum: international refugee law and the globalisation of migration control. Cambridge: Cambridge University Press, 2011.

GOODWIN-GILL, G. S.; MCADAM, J. The refugee in international law. 3. ed. Oxford: Oxford University Press, 2007.

GUSTIN, M. B. de S. (Re)pensando a pesquisa jurídica: teoria e prática. 3. ed., rev. e atual. Belo Horizonte: Del Rey, 2010.

G1. Hungria termina construção de barreira na fronteira com a Sérvia. 29 ago. 2015. Disponível em: 〈http://g1.globo.com/mundo/noticia/2015/08/hungria-termina-construcao-de-barreira-nafronteira-com-servia.html〉. Acesso em: 26 mar. 2017.

HEE, M.; SOBRINO, M. da S. Soberania no direito internacional: evolução ou revolução? Revista de Informação Legislativa, Brasília, v. 41, n. 163, p. 7-29, jul./set. 2004. Disponível em: 〈http:// www2.senado.leg.br/bdsf/item/id/975>. Acesso em: 07 jul. 2015.

KAKISSIS, J. Greek border fence to keep out illegal immigrants? Time, Athens, 07 Jan. 2011. Disponivel em: 〈http://content.time.com/time/world/article/0,8599,2040821,00.html〉. Acesso em: 26 jul. 2015. 
LAVANCHY, P. ACNUR e América Latina: estratégias regionais e soluções aos problemas no continente. Genebra, 2004. Disponivel em: 〈https://www.justica.gov.br/central-de-conteudo/ estrangeiros/art_lavanchy.pdf>. Acesso em: 26 mar. 2017.

LUZ FILHO, J. F. S. Non-refoulement: breves considerações sobre o limite jurídico à saída compulsória do refugiado. In: ALMEIDA, G. A. de; ARAÚJO, N. de (Org.). 0 direito internacional dos refugiados: uma perspectiva brasileira. Rio de Janeiro: Renovar, 2001.

LYMAN, R. Bulgaria puts up a new wall, but this one keeps people out. The New York Times, Lesovo, 05 Apr. 2015. Disponível em: 〈http://www.nytimes.com/2015/04/06/world/europe/ bulgaria-puts-up-a-new-wall-but-this-one-keeps-people-out.html?_r=1>. Acesso em: 27 jul. 2015.

MAZZUOLI, V. de O. Soberania e a proteção internacional dos direitos humanos: dois fundamentos irreconciliáveis. Revista de Informação Legislativa, Brasília, v. 39, n. 156, p. 169-177, out./dez. 2002. Disponivel em: 〈http://www2.senado.leg.br/bdsf/item/id/823〉. Acesso em: 07 jul. 2015.

MIGRAMUNDO. Conector volta a mostrar situação precária de migrantes no Brasil e necessidade de nova Lei de Migração, 29 set. 2016. Disponível em: 〈http://migramundo.com/conector-voltaa-mostrar-situacao-precaria-de-migrantes-no-brasil-e-necessidade-de-nova-lei-de-migracao/〉. Acesso em: 08 jun. 2017.

MOREIRA, J. B. A problemática dos refugiados na América Latina e no Brasil. Cadernos PROLAM/ USP, v. 2, n. 4, p. 57-56, 2005. Disponível em: 〈http://www.usp.br/prolam/downloads/2005_2_3. pdf>. Acesso em 04 mar. 2017.

PIOVESAN, F. Direitos humanos e o direito constitucional internacional. 14. ed., rev. e atual. São Paulo: Saraiva, 2013.

PIRJOLA, J. Shadows in paradise - Exploring non-refoulement as an open concept. Oxford: Oxford University Press, 2008. Disponível em: 〈http://www.eui.eu/Documents/DepartmentsCentres/ AcademyofEuropeanLaw/CourseMaterialsHR/HR2010/Chetail/ChetailReading4.pdf . Acesso em: 09 jan. 2015.

PÓVOA NETO, H. Barreiras físicas à circulação como dispositivos de política migratória: notas para uma tipologia. Núcleo Interdisciplinar de Estudos Migratórios (Niem), Instituto de Pesquisa e Planejamento Urbano e Regional da Universidade Federal do Rio de Janeiro (Ippur-UFRJ), 2007. Disponível em: 〈http://www.abep.nepo.unicamp.br/docs/anais/outros/5EncNacSobreMigracao/ mesa_03_bar_fis_circ.pdf〉. Acesso em: 02 jul. 2015.

REZENDE, A. C. Vocabulário jurídico e multidisciplinar. Campinas: Copola Livros, 2002.

STOYANOVA, $V$. The principle of non-refoulement and the right of asylum-seekers to enter state territory. Interdisciplinary Journal of Human Rights Law, v. 3, n. I, 2008. Disponível em: 〈http:// www.americanstudents.us/IJHRL3/Articles/Stoyanova.pdf). Acesso em: 31 mar. 2014.

TREVISANUT, S. The principle of non-refoulement at sea and the effectiveness of asylum protection. In: VON BOGDANDY, A.; WOLFRUM, R. (Ed.). Max Planck Yearbook of United Nations Law. Leiden: Koninklijke Brill N.V., v. 12, 2008. Disponível em: 〈http://www.mpil.de/files/pdf3/ mpunyb_05_trevisanut_12.pdf〉. Acesso em: 20 jul. 2015.

UNHCR - United Nations High Commissioner for Refugees. UNHCR concerned by border practices after deaths of two Iraqis at the Bulgaria-Turkey border, Geneva, 31 Mar. 2015. Disponivel em: 〈http://www.unhcr.org/551abb606.html〉. Acesso em: 27 jul. 2015.

Advisory opinion on the extraterritorial application of non-refoulement obligations under the 1951 convention relating to the status of refugees and its 1967 protocol. Geneva, 26 January 2007. Disponivel em: 〈http://www.refworld.org/pdfid/45f17a1a4.pdf〉. Acesso em: 17 jan. 2015. 
Background note on the protection of asylum-seekers and refugees rescuedat sea (final version, including annexes), [s.l.], 18 March 2002. Disponivel em: 〈http://www.refworld. org/docid/3cd14bc24.html. Acesso em: 22 jul. 2015.

Hungary as a country of asylum: observation son restrictive legal measures and subsequent practice implemented between July 2015 and March 2016, [s.l.], May 2016. Disponível em: $\langle$ http://www.refworld.org/docid/57319d514.html?utm_source=Briefing+Notes++++15+July+2016\&utm_medium=email\&utm_term=otero@unhcr.org\&utm_content=UN+High+C ommissioner+for+Refugees+(UNHCR)\%2c+Hungary+as+a+country+of+asylum.+Observations +on+restrictive+legal+measures+and+subsequent+practice+implemented+between+July+201 $5+$ and+March+2016\%2c+May+2016\&utm_campaign=\#_ga=1.170424608.1833066331.1453321 383>. Acesso em: 26 mar. 2017.

. International Convention Relating to Stowaways ("Brussels Convention"), 10 October 1957. Disponível em: 〈http://www.refworld.org/docid/3ae6b3a80.html». Acesso em: 20 jul. 2015.

. The principle of non-refoulement as a norm of customary international law. Response to the Questions Posed to UNHCR by the Federal Constitutional Court of the Federal Republic of Germany in Cases 2 BvR 1938/93, 2 BvR 1953/93, 2 BvR 1954/93, [s.l.], 31 January 1994. Disponivel em: 〈http://www.refworld.org/docid/437b6db64.html〉. Acesso em: 28 dez. 2014.

. UNHCR global appeal 2015 update - Lebanon, 01 December 2014. Disponível em: 〈http://www.unhcr.org/5461e607b.html. Acesso em: 24 jul. 2015.

. UNHCR mid-year trends 2014, January 2015. Disponível em: 〈http://www.refworld. org/docid/54ace79b4.html>. Acesso em: 24 jul. 2015.

. UNHCR observation son the current asylum system in Bulgaria, April 2014. Disponivel em: 〈http://www.refworld.org/docid/534cd85b4.html〉. Acesso em: 27 jul. 2015.

UNHCR observation son the current asylum system in Greece, December 2014. Disponivel em: 〈http://www.refworld.org/docid/54cb3af34.html〉. Acesso em: 25 jul. 2015.

. UNHCR observation son the situation asylum-seekers and refugees in Hungary, April 2012. Disponivel em: 〈http://www.refworld.org/pdfid/4f9167db2.pdf〉. Acesso em: 28 jul. 2015.

UNITED NATIONS TREATY COLLECTION. Convention relating to the Status of Refugees, Chapter V: Refugees and State less Persons. Geneva, 28 July 1951. Disponivel em: 〈https://treaties.un.org/ Pages/ViewDetailsII.aspx?src=TREATY\&mtdsg_no=V-2\&chapter $=5 \&$ Temp $=$ mtdsg2\&lang=en . Acesso em: 15 jan. 2015.

UNITED STATES SUPREME COURT. INS v. Cardoza-Fonseca, 480 U.S. 421 (1987). Washington D.C., 09 March 1987. Disponivel em: 〈https://supreme.justia.com/cases/federal/us/480/421/case. html>. Acesso em: 14 jan. 2015.

. Sale v. Haitians Ctrs. Council, Inc., 509 U.S.155 (1993). Washington D.C., 21 June 1993. Disponível em: 〈http://caselaw.lp.findlaw.com/scripts/getcase.pl?court=US\&vol=509\&invol=155». Acesso em: 13 jan. 2015.

UN NEWS CENTRE. UN report: 5.5 million displaced by war in first half of 2014, setting record, 07 jan. 2015. Disponível em: 〈http://webcache.googleusercontent.com/search?q=cache: 2lwcP4Ap1rUJ:www.un.org/apps/news/story.asp\%3FNewsID\%3D49742+\&cd=5\&hl=ptBR\&ct=clnk\&gl=br\#.VLunO0fF9_8〉. Acesso em: 17 jan. 2015. 


\title{
Sobre a autora
}

Laís Gonzales de Oliveira é mestranda e bacharela em Direito na Faculdade de Direito de Ribeirão Preto, da Universidade de São Paulo (USP). Advogada e técnica legislativa da Câmara Municipal de Pradópolis-SP.

\section{Endereço para correspondência}

Rua Pedro Biagi, n. 1196, Jardim Sumaré

14.170-540 - Sertãozinho-SP, Brasil

\begin{abstract}
Borders barriers against the principle of non-refoulement: the inaccessibility of the territory and of the refugee status determination
\end{abstract}

This study sought to determine whether the principle of non-refoulement would apply to individuals not formally recognized as refugees, and whether the prevention of access to the target state's territory would violate such principle, besides analyzing the sovereign exercise of migration control with the threat of the non-refoulement and the human rights protected by it. Hereby, we ran a theoretical, bibliographical and documentary research,, with critical and dogmatic analyses of imperative normative instruments of international law concerning the protection of refugees; of the guidelines from international organizations and legal precedence on the subject. Subsequently, we ran a contextualized study with a brief analysis of some recent cases in which barriers were employed as migration control mechanisms. As a jus cogens and customary rule of international law, the principle proves to be applicable regardless of formal recognition of refugee status, relativizing national sovereignty. Despite divergences in the application of the principle, the instating of border barriers violates the principle, since access to the target state's territory may be needed for the process of determining refugee status to be fair and effective.

Keywords: Principle of non-refoulement. Asylum-seekers. Border barriers. Migration control. Human rights.

\section{Resumen}

Barreras fronterizas contra el principio de no devolución: la inaccesibilidad del territorio y de la determinación de la condición de refugiado

Este estudio trata de determinar si el principio de no devolución se aplicaría a los individuos no reconocidos oficialmente como refugiados y si la denegación de acceso al territorio del Estado de destino violaría este principio, además de analizar el ejercicio soberano de control migratorio ante la amenaza de no devolución y los derechos humanos protegidos por ella. Para eso se desarrolló una investigación teórica, bibliográfica y documental, con un análisis crítico-dogmático de los instrumentos normativos imperativos del derecho internacional para la protección de los refugiados, de las directrices de las organizaciones internacionales y de los antecedentes 
judiciales sobre el tema. Posteriormente, se elaboró un estudio contextualizado con un breve análisis de los casos recientes en los que se hayan empleado las barreras fronterizas como mecanismos de control de la migración. Como norma jus cogens y consuetudinaria del derecho internacional, el principio se demuestra aplicable independientemente del reconocimiento formal de la condición de refugiado, relativizando la soberanía nacional. A pesar de la divergencia en la aplicación del principio, la imposición de barreras fronterizas viola el principio de no devolución ya que el acceso al territorio del Estado de destino es necesario para que el proceso de determinación de la condición de refugiado sea justo y eficaz.

Palabras clave: Principio de no devolución. Solicitantes de asilo. Barreras fronterizas. Control de la migración. Derechos humanos.

Recebido para publicação em 11/07/2016 Aceito para publicação em 12/06/2017 